\title{
Switching gears for the sustainable development goals
}

\author{
In the face of an on-going global pandemic and the growing urgency of climate change, the challenge of \\ building an equitable and sustainable world has never been greater. Thus, now more than ever, we want \\ to support and highlight research efforts made at attaining the UN sustainable development goals.
}

n 2015 the sustainable development goals (SDGs) were set by the UN to tackle endemic issues in how humanity can live both sustainably and fairly. A total of 17 goals were agreed upon ranging from eliminating poverty, inequality and hunger to taking action on climate change. After almost six years and the upheavals to everyday life since, the need to attain these goals by 2030 remains will be reached by 2030, they remain a vital framework towards making global progress towards equality. view neglects, however, that many current practices are necessary for a large part of the global population to fulfill their basic needs. Thus, solutions have to be adapted and developed in a manner that is sustainable for all populations and all countries - these are likely to be complex and costly. While some of the SDGs require technological solutions, most will need systematic transformations of societies to address income and gender inequality or building sustainable institutions. A truly sustainable world is one that is equitable and just.

The problems the world faces are complex, multifaceted and unlikely to be solved by a single solution, a solitary initiative or one point of view. More than ever, scientific fields need to talk not to each other but with each other, along with extending the conversation to policy makers, stakeholders and the communities impacted by the challenges the world faces. One of the keys to achieving the SDGs will be interdisciplinary, multidisciplinary and transdisciplinary research bringing together different ideas and approaches from across the sciences. While the necessity of such approaches is increasingly acknowledged, many studies are still predominantly contained within the borders of traditional disciplines. Nor can any single one of the 17 SDGs be separated from the others, as the goals of each are bound to the progress of them all. For instance, achieving Zero hunger (SDG 2) requires significant progress in reduction in poverty (SDG 1), action on climate change to reduce weather extremes (SDG 13) and protection of life on land and water (SDG 14 and 15). As a multidisciplinary journal, we want to support further the relevant research.

In a first step, we are launching a series of thematic collections that brings together 
content from across the journal in the physical, Earth, life, health and social sciences. Each collection will highlight research and opinion to explore the causes, impacts and solutions for translation into policy. By bringing this research from across the breadth of the sciences together, we want to highlight that living in a sustainable and fair world is not just the preserve of any single field of research, but an opportunity for diverse communities of researchers to embrace addressing the challenges by working together.

We are pleased to launch this series in the coming weeks with Clean Air. This curated collection of research, commentaries and interviews will explore the complex problem of air pollution and how using the SDGs framework could be part of the solution. In upcoming SDG thematic collections, as we explore the challenges facing the world - ranging from the food we eat, the energy we need, and to the protection of the land and water around us - and ultimately how to achieve a sustainable and equitable economy and society, we invite our authors, reviewers and readers to consider their work in the context of the SDGs and how it can contribute to accomplishing these goals.

Published online: 05 July 2021

\section{References}

1. Tollefson, J. "COVID curbed carbon emissions in 2020 - but not by much" Nature 589, 343 (2021). https://doi.org/10.1038/d41586-02100090-3.

2. The Lancet Public Health. "COVID-19-break the cycle of inequality" The Lancet Public Health Volume 6, Issue 2 (2021). https://doi.org/ 10.1016/S2468-2667(21)00011-6.

3. The World Bank. "Decline of Global Extreme Poverty Continues but Has Slowed: World Bank" (2018). https://www.worldbank.org/en/news/ press-release/2018/09/19/decline-of-globalextreme-poverty-continues-but-has-slowedworld-bank.

4. The World Health Organization " 1 in 3 people globally do not have access to safe drinking water - UNICEF, WHO” (2018). https://www.who.int/ news/item/18-06-2019-1-in-3-people-globallydo-not-have-access-to-safe-drinking-waterunicef-who.

5. Nature "Time to revise the Sustainable Development Goals” Nature 583, 331-332 (2020). https://doi.org/10.1038/d41586-020-02002-3.

(c) (i) Open Access This article is licensed under a Creative Commons Attribution 4.0 International License, which permits use, sharing, adaptation, distribution and reproduction in any medium or format, as long as you give appropriate credit to the original author(s) and the source, provide a link to the Creative Commons license, and indicate if changes were made. The images or other third party material in this article are included in the article's Creative Commons license, unless indicated otherwise in a credit line to the material. If material is not included in the article's Creative Commons license and your intended use is not permitted by statutory regulation or exceeds the permitted use, you will need to obtain permission directly from the copyright holder. To view a copy of this license, visit http:// creativecommons.org/licenses/by/4.0/.

(C) Springer Nature Limited 2021 